\title{
AVALIAÇÃO PSICOLÓGICA E IDENTIFICAÇÃO DAS ALTAS \\ HABILIDADES/SUPERDOTAÇÃO NA VIDA ADULTA
}

\author{
Karina Nalevaiko Rocha* \\ Karina Inês Paludo** \\ Solange Muglia Wechsler ${ }^{* * *}$
}

\begin{abstract}
RESUMO: O processo de identificação e avaliação das AH/S estabelece-se como um desafio e de suma importância em qualquer fase da vida, sobretudo na vida adulta, permitindo encaminhamentos e intervenções adequadas. Considerando a relevância do tema e a carência de produções nacionais, este estudo teve como objetivo descrever e analisar um estudo de caso de avaliação de AH/S de uma paciente adulta da cidade de Curitiba-PR. A avaliação foi composta por instrumentos psicológicos quantitativos e instrumentos qualitativos para investigação da superdotação, além de informações advindas da família. Os dados revelam altos índices nos testes de desempenho de inteligência, memória e atenção. Quanto aos aspectos emocionais, a avaliada demonstra a presença de certo nível de ansiedade, baixa autoestima e postura autocrítica. Quanto aos aspectos de criatividade, apresenta estilo preferencial inconformista transformador. No que tange ao perfil das $\mathrm{AH} / \mathrm{S}$, a avaliada evidenciou habilidade acima da média, envolvimento com a tarefa e criatividade, o que corrobora que ela apresenta comportamentos de superdotação, nos pressupostos teóricos de Renzulli (2014). Os dados levantados propiciaram à avaliada maior autoconhecimento e ressignificação de crenças a seu próprio respeito, fortalecendo sua autoestima, favorecendo encaminhamentos e direcionamentos na vida pessoal e profissional, contribuindo com o desenvolvimento, expressão e valorização do seu potencial.
\end{abstract}

PALAVRAS-CHAVE: Altas habilidades/superdotação; Adultos; Identificação; Avaliação Psicológica.

\section{PSYCHOLOGICAL ASSESSMENT AND IDENTIFICATION OF GIFTEDNESS IN ADULT LIFE}

\begin{abstract}
The process of identification and evaluation of the High Abilities/Giftedness is settled as a challenge of major importance in any stage of life, especially in adult life, allowing adequate referrals and interventions. Considering the relevance of the theme and the lack for national productions, this study aimed to describe and analyze an AH/S evaluation case study of an adult patient in the city of Curitiba-PR. The evaluation was composed of quantitative and qualitative psychological instruments for investigation of the giftedness, in addition to information from the family. The data showed high rate in the intelligence, memory and attention performance tests. About the emotional aspects, the evaluated shows a certain level of anxiety, low self-esteem and self-critical posture. In terms of creativity aspects, shows preference for nonconformist and transformative style. As for the $\mathrm{AH} / \mathrm{S}$ profile, the evaluated revealed ability above average, engagement with the task and creativity, what corroborates the presented behaviors of giftedness in the theoretical assumptions of Renzulli (2014). The gathered data provided the evaluated with greater self-knowledge and resignification of beliefs, strengthening her selfesteem, favoring routing and directions in her personal and professional life, contributing to the development, expression and valorization of her potential.
\end{abstract}

KEYWORDS: Giftedness; Adults; Psychological Identification; Assessment.

\footnotetext{
* Doutoranda em Psicologia pela PUC-Campinas. Email: kanalevaiko@gmail.com. Orcid: 0000-0002-1385-7498.

** Doutora e Mestre em Educação pela Universidade Federal do Paraná (UFPR). Professora da Pontifícia Universidade Católica-Paraná (PUC-PR) e Diretora Executiva do Talentos Instituto da Criança. E-mail: karina paludo@hotmail.com. Orcid: 0000-0002-4685-4525.

*** Doutora em Psicologia e professora do Programa de Pós-Graduação em Psicologia da PUC-Campinas. E-mail: wechsler@lexxa.com.br. Orcid: 0000-0002-9757-9113.
} 


\section{Introdução}

As altas habilidades/superdotação (AH/S) versam sobre a condição humana na qual o sujeito apresenta um potencial/desempenho acima do que espera para sua faixa etária (ALENCAR; FLEITH, 2001). Na perspectiva de Renzulli (2004), compreende-se o comportamento de superdotação como o resultado da intersecção entre três anéis, a saber: habilidade acima da média, criatividade e envolvimento com a tarefa.

A habilidade acima da média abarca tanto a habilidade geral quanto a habilidade específica. A primeira, habilidade geral, refere-se à "capacidade de utilizar o pensamento abstrato ao processar informação e de integrar experiências que resultem em respostas apropriadas e adaptáveis a novas situações” (VIRGOLIM, 2007, p. 33). A segunda, habilidade específica, por sua vez, relaciona-se à “[...] habilidade de aplicar várias combinações das habilidades gerais a uma ou mais áreas especializadas do conhecimento ou do desempenho humano, como dança, fotografia, liderança, matemática, composição, musical [...]” (Ibidem, p. 33). O envolvimento com a tarefa pode ser entendido como motivação, vinculação e empenho dedicados em uma área de interesse, evidenciado por autoconfiança, perseverança e dedicação (VIRGOLIM, 2007). A criatividade versa sobre a capacidade de apresentar ideias originais, divergentes, além de curiosidade e flexibilidade de pensamento (ALENCAR; FLEITH, 2001).

Compreende-se a relação direta entre superdotação e inteligência. Durante muito tempo, o conceito de inteligência atrelava-se à interpretação unidimensional, reduzindo-se a altos escores nos testes padronizados. A superdotação, deste modo, era definida e caracterizada neste molde. Entretanto, o avanço da ciência ampliou o entendimento sobre o constructo de inteligência para uma visão multidimensional, levando em consideração, inclusive, as diferentes influências na constituição do sujeito (ALENCAR, FLEITH, 2001; PANZERI, 2012; PALUDO, 2014).

Neste sentido, pode-se admitir que inteligente não é mais exclusivamente a pessoa que apresenta altos escores nos testes de coeficiente intelectual (QI), aceitando que um mesmo sujeito pode ter uma habilidade superior em uma área do conhecimento, posicionar-se na média em outras, ou ainda, apresentar dificuldades em quaisquer campos do saber.

A concepção multifatorial de inteligência acarretou mudanças na maneira se compreender a superdotação. Tem-se a superação da supervalorização do domínio cognitivo em detrimento de outros aspectos, reconhecendo a influência de questões emocionais, de personalidade e ambientais no processo de formação e manifestação do potencial.

O entendimento reformulado de inteligência traz um impacto significativo no modo de se entender, conceituar, avaliar e identificar a superdotação. $\mathrm{O}$ estudo das AH/S ao longo de décadas permitiu uma compreensão ampliada sobre o processo de identificação, considerando aspectos que vão além de medidas de desempenho, como por exemplo a análise quantitativa do QI, aferido pelos 
tradicionais testes de inteligência (CAMPOS et al, p2019; HERTZOG et al, 2018). Além disso, passa-se a considerar aspectos do seu funcionamento emocional e social, habilidades sociais, inteligência emocional e seus potenciais, chamados de forças e virtudes (PFEIFFER, 2018). Desta forma, avaliações atuais tendem a considerar diferentes instrumentos e construtos, uma vez que possibilitam melhor compreensão do potencial e do funcionamento do indivíduo, além de direcionar encaminhamentos e diretrizes para intervenções adequadas (COSTA; LUBART, 2016).

Há muitos desafios para a identificação de $\mathrm{AH} / \mathrm{S}$ na idade adulta, no entanto é possível estabelecer alguns domínios, como: grande produção de ideias, busca de soluções próprias e inovadoras para os problemas; alta capacidade de análise e crítica, independência de pensamento; grande produção de ideias; concentração prolongada numa atividade de interesse; consciência de si mesmo e de suas diferenças; desgosto com a rotina; gosto pelo desafio; habilidade em áreas específicas; interesse por assuntos e temas complexos e persistência perante dificuldades inesperadas (PÉREZ, 2008). Assim, considerando as $\mathrm{AH} / \mathrm{S}$ um tema amplo, heterogêneo, com muitos domínios e diferentes formas de manifestação em todas as fases de desenvolvimento humano, constata-se que o processo de identificação é complexo e muitas vezes, negligenciado durante toda a trajetória escolar e acadêmica (BRODY, 2017).

A ausência de avaliação e intervenção precoce pode não oferecer propostas e um atendimento diferenciado que possam atender as necessidades específicas de desenvolvimento das $\mathrm{AH} / \mathrm{S}$, acarretando na inibição de seu potencial. Ali e Rafi (2016) o denominam de sub-realizadores, ou seja, tratam-se de superdotados que têm uma grande diferença entre potencial e desempenho, ou seja, suas habilidades não se desenvolveram em talentos efetivamente. Deve-se considerar que além dos prejuízos em aspectos cognitivos, relacionados a um desempenho inferior em relação às capacidades de raciocínio, processamento de informação e criatividade, há também prejuízos emocionais, ou seja, o superdotado poderá revelar sentimentos de baixa autoestima, inferioridade, desmotivação e propósito para realizar determinadas atividades. Mosquera, Stobäus e Freitas (2013, p. 404) sugere a existência de dois tipos de adultos com altas habilidades/superdotação: os superdotados adaptados e os não-adaptados, esta diferenciação cria a grande expectativa de que é necessário educar estas pessoas desde crianças, para que possam ter um melhor encaminhamento em suas vidas desde cedo.

Pérez (2008) ressalta que as características da superdotação permanecem presentes na vida adulta e, ora são percebidos como atributos ora como defeitos, no entanto, superdotados adultos relatam o alívio do reconhecimento e a angústia do não reconhecimento que se acomodam na percepção do assincronismo pessoa-sociedade, fundamental para compreender se e como se constrói a identidade como superdotado, muitas vezes tentando suavizar, com o conforto na "normalidade".

Desta forma, é de suma importância a identificação das AH/S em qualquer momento da vida, pois permite encaminhamentos e intervenções adequadas. Neste sentido, destaca-se a relevância de se pensar no processo de avaliação e identificação do sujeito superdotado na vida adulta, como uma possibilidade de autoconhecimento e ressignificações de experiências e promoção do potencial. Estudo 
longitudinal conduzido por Pérez \& Freitas (2012) indica que a identificação formal das AH/S na vida adulta foi um fator decisivo na aceitação, reconhecimento dos indicadores da superdotação e uma construção positiva da identidade em mulheres. Diante do exposto, apresenta-se nesta oportunidade uma discussão em torno do processo de avaliação psicológica e identificação de sujeitos superdotados na vida adulta, tendo em vista a carência desse recorte de produção no contexto brasileiro.

\section{Os desafios na identificação da $\mathrm{AH} / \mathrm{S}$ na vida adulta}

A heterogeneidade encontrada na população de pessoas com AH/S está atrelada à variabilidade de habilidades cognitivas, atributos de personalidade e nível de desempenho. A referida variabilidade de características revela a complexidade inerente ao processo de identificação das $\mathrm{AH} / \mathrm{S}$. Este cenário pode ser ainda mais desafiador quando se pensa no sujeito adulto, visto que, muitas vezes, sua trajetória e experiências de vida concorrem para abafar o seu potencial.

Assim, destaca-se a avaliação psicológica como um recurso importante para identificar e promover o desenvolvimento de adultos superdotados. A avaliação psicológica é um processo sistemático de conhecimento a respeito do funcionamento psicológico do sujeito, de tal forma a gerar hipóteses, orientar ações e decisões futuras (PRIMI, 2010). Dito isso, para uma atuação adequada, as intervenções devem ser precedidas de avaliações (NORONHA, 2002), ou seja, o diagnóstico para o terapeuta, deve ter a mesma função que o bastão para um equilibrista, pois é ele a base que dará suporte ao psicólogo para uma intervenção adequada (FERNANDÉZ, 1991).

A área de avaliação psicológica já apresentou diversos dilemas éticos e deontológicos em relação à formação, atuação, pesquisa e publicação de material para avaliação psicológica. No entanto, desde a década de 90 a American Psychological Association (APA) estabeleceu princípios éticos básicos a serem seguidos nos diferentes âmbitos da Psicologia e, em menor abrangência, os Códigos de Ética das associações de classe também buscam delinear práticas e padrões éticos importantes (APA, 1999). O International Test Commission (2010) criou um guia orientador a ser utilizado pelos profissionais da área de avaliação psicológica, no qual trata especificamente dos critérios mínimos a serem observados para atuação nessa área, contendo orientações para tradução e adaptação de testes.

No Brasil, em 2001 foi estabelecido o Sistema de Avaliação de Testes Psicológicos (SATEPSI), órgão criado e alimentado pelo Conselho Federal de Psicologia para divulgar informações sobre os testes psicológicos à comunidade e profissionais. Trata-se de um sistema de certificação de instrumentos de avaliação psicológica para uso profissional, que analisa e qualifica os instrumentos (CFP, 2004).

Pode-se constatar uma preocupação em relação à cientificidade dos instrumentos psicológicos utilizados no processo de avaliação e, para tal, consideram-se dois aspectos fundamentais: o conceito de validade e fidedignidade. Por validade entende-se o alcance em que o teste mensura o que se propõe a medir, ou seja, o conhecimento do que o teste mede e de quão bem faz isso (ANASTACI; URBINA, 
2000). Se um instrumento não possui evidências de validade, não há segurança de que as interpretações sobre as características psicológicas das pessoas sugeridas por suas respostas na testagem são legítimas (PRIMI, 2010). Quanto ao conceito de fidedignidade, busca-se sua precisão, ou seja, a estabilidade com que os escores dos testandos conservam-se em aplicações alternativas de um mesmo teste ou em formas equivalentes de testes distintos. Assim, o teste deve ser capaz de produzir escores que diferenciam testandos com diferentes graus de habilidade (PRIMI, 2010).

O processo de avaliação psicológica, realizado por meio de instrumentos e recursos válidos e fidedignos, abarcando informações quanti e qualitativas, possibilita a identificação da pessoa superdotada. Por meio da avaliação psicológica reúne-se um conjunto de traços e características individuais que, à luz da teoria, possibilita o reconhecimento do sujeito superdotado.

Neste sentido, cabe destacar a necessidade de o processo de avaliação psicológica voltado para a investigação da condição das AH/S estar fundamentado em uma concepção de inteligência e de altas habilidades/superdotação. Isto posto, adota-se, nesta oportunidade, os pressupostos teóricos de Howard Gardner (2000) acerca do constructo de inteligência e de Joseph Renzulli que amparado o entendimento acerca do comportamento de superdotação (2004; 2014).

Diante da importância da identificação das altas habilidades/ superdotação, sobretudo na vida adulta, considerando os desafios e dificuldades inerentes a este processo, este estudo teve como objetivo descrever e analisar um estudo de caso de avaliação de AH/S de uma paciente adulta da cidade de Curitiba-PR.

Buscou-se ainda, enfatizar a importância da condução deste processo considerando diferentes constructos, obtendo uma avaliação completa e integral sobre o perfil da avaliada e procurou demonstrar a importância desta avaliação em qualquer momento da vida do indivíduo, em especial na vida adulta, visando garantir maior autoconhecimento e direcionamento na vida pessoal e profissional.

\section{Método}

Para alcançar os objetivos supracitados, será realizada a descrição de um estudo de caso clínico de uma paciente ${ }^{1}$, apresentada com nome fictício para preservação do sigilo da identidade. Em seguida, serão descritos os instrumentos utilizados, os construtos avaliados, as ações referentes ao processo de avaliação e a análise dos resultados.

\footnotetext{
${ }^{1}$ Estudo realizado a partir do projeto intitulado "Identificação das habilidades intelectuais e criativas por testes psicológicos e indicação de professores" sob o número 13190119.3.0000.5481.
} 


\section{Resultados}

\section{Descrição e apresentação do caso}

Susan tem 25 anos, é casada e não tem filhos. Sempre estudou em escola particular e graduou-se em engenharia. Trabalha em uma empresa em sua área de formação, no entanto, comenta não se sentir realizada na função exercida. Sua mãe buscou a avaliação, pois percebe Susan frustrada com a profissão e sem autoconhecimento sobre suas habilidades e competências, com a tendência de subvalorizar seu potencial. Em entrevista com a mãe, a mesma relata que a filha sempre se destacou na escola, apresenta um raciocínio rápido, facilidade de aprendizado, de compreensão e interesses diversos. A mãe acredita que este é um fator que pode dificultar o direcionamento de sua carreira, causando-lhe frustração e cansaço. As características supracitadas sugerem a hipótese de Susan ser uma pessoa com a condição de superdotação. Dito isso, o processo de avaliação neuropsicológica teve como premissa conhecer o perfil e potencial de Susan com o intuito de contribuir para o seu autoconhecimento e resposta sobre a hipótese de ela apresentar $\mathrm{AH} / \mathrm{S}$.

\section{O processo de avaliação psicológica}

A avaliação de Susan foi multidisciplinar, considerando as áreas da Psicologia e Pedagogia, com duas profissionais com expertise em superdotação, sendo considerados os aspectos mais importantes dos resultados psicológicos para o presente trabalho.

O processo ocorreu entre agosto e novembro de 2019, compreendendo 12 sessões de 1 hora realizadas semanalmente, conforme disponibilidade de horário da avaliada, fato que impactou em um período maior de avaliação do que o habitual.

A perspectiva de avaliação psicológica adotada foi multifatorial e englobou diferentes domínios, considerando aspectos cognitivos, socioemocionais, neuropsicológicos e criativos. O processo de avaliação levou em conta dados relacionados à avaliação clínica de comportamentos observados e instrumentos validados e padronizados para a população brasileira. Todos os testes utilizados na avaliação estão aprovados pelo SATEPSI, com uso regulamentado à prática do psicólogo. Os domínios e os instrumentos utilizados foram:

Área cognitiva: Escala de Inteligência Wechsler para adultos - WAIS III (WECHSLER, 2004)'; Teste Não Verbal de Inteligência G-36 (BOCCALANDRO, 2003).

\footnotetext{
${ }^{2}$ Ressalta-se que a avaliação ocorreu em agosto de 2019, período em que o instrumento WAIS III era favorável e com estudos válidos para utilização do psicólogo.
} 
Atenção e Memória: Bateria Psicológica para Avaliação da Atenção - BPA (RUEDA, 2013); Figuras Complexas de Rey - Teste de cópia e reprodução de memória de figuras geométricas complexas (OLIVEIRA; RIGONI, 2014);

Emocionais e de personalidade: Casa- Árvore- Pessoa - Técnica Projetiva de Desenho (HTP) (ALVES; TARDIVO, 2003); Inventário Fatorial de Personalidade - IFP (LEME; RABELO; ALVES, 2013);

Criatividade: Estilos de Criar e Pensar (WECHSLER, 2006).

Além dos instrumentos restritos à área da Psicologia, adotaram-se inventários para investigação de indicadores de $\mathrm{AH} / \mathrm{S}$, a saber: Questionário de Identificação de Indicadores de Altas Habilidades/Superdotação - Adulto - QIIAHSD - A e Questionário de Identificação de Indicadores de Altas Habilidades/Superdotação - Adulto - QIIAHSD - A - 2 a fonte (PÉREZ; FREITAS, 2016).

\section{Resultados alcançados}

\section{Aspectos Cognitivos}

A avaliação do potencial intelectual foi realizada através do instrumento formal Escala de Inteligência Wechslerpara Adultos - WAIS III (WECHSLER, 2004). Trata-se de um instrumento clínico, um dos mais importantes testes para avaliação da capacidade intelectual de adultos (PESSOTTO; BARTHOLOMEU, 2019). O instrumento fornece informações sobre os QIs Total, de Execução e Verbal, bem como o índice de compreensão verbal, índice de organização perceptual, índice de memória operacional e índice de velocidade e amplitude de processamento. Compreende quatorze subtestes, a saber: completar figuras, vocabulário, códigos, semelhanças, cubos, aritmética, raciocínio matricial, dígitos, informação, arranjo de figuras, compreensão, procurar símbolos, sequência números-letras e armar objetos.

Susan alcançou uma classificação Muito Superior na avaliação quantitativa em QI verbal, pontos ponderados 130 e percentil 98. O QI de execução também tem classificação Muito Superior, pontos ponderados 129 e percentil 98 e no QI Total, alcançando percentil 98, pontos ponderados 131.

A compreensão verbal e organização perceptual relacionam-se com o raciocínio fluído, fundamentais para avaliação cognitiva e relacionados às habilidades de manipulação de abstrações, regras, generalizações e relacionamentos lógicos (CARROLL, 1993). A avaliação da compreensão verbal é realizada através de 3 subtestes: vocabulário, semelhanças e informação.

A avaliação da organização perceptual é obtida através dos seguintes subtestes: completar figuras, cubos e raciocínio matricial. Relaciona-se com a capacidade de analisar, sintetizar e reproduzir um estímulo visual abstrato tridimensional, formar grupos com características comuns e identificação de detalhes omitidos em figuras sociais.

Em compreensão verbal, Susan apresenta um desempenho de 133 pontos ponderados, percentil 99 e classificação muito superior. Em organização perceptual, Susan tem 129 pontos ponderados, percentil 98 e classificação muito superior. 
No que versa sobre a memória operacional, é avaliada através dos subtestes aritmética, dígitos e sequência de número-letras. Estudos atuais demonstram que a memória operacional é um componente essencial aos processos cognitivos e diretamente relacionado ao aprendizado e realizações (PERLOW; JATTUSO; MOORE, 1997). Refere-se à habilidade de manter-se consciente da informação recebida, desenvolver uma atividade, manipulá-la e a partir dela produzir resultados (WECHSLER, 2013).

Susan apresenta 121 pontos ponderados, percentil 92 e classificação superior. Mostra facilidade relacionada à memória auditiva de curto prazo, sequenciamento, atenção e concentração. Esse dado indica que tem facilidade para atividades que demandem compreensão e memória remota.

A velocidade perceptual é avaliada através dos subtestes códigos e procurar símbolos. Pesquisas indicam que a velocidade de processamento das informações está diretamente relacionada à capacidade mental, ao desenvolvimento, desempenho em leitura e raciocínio (KAIL, 2000). Susan apresenta 135 pontos ponderados, percentil 99 e classificação muito superior.

Além do WISC - III, aplicou-se o Teste Não Verbal de Inteligência - G36. Ele busca avaliar o fator $G$ de inteligência. Apresenta itens em ordem crescente de dificuldade, envolvendo os seguintes raciocínios: compreensão de relação de identidade e raciocínio por analogia, analogia do tipo numérica com adição e subtração, mudança de posição e analogia espacial com mudança de posição (BOCCALANDRO, 2003). As respostas de Susan alcançam o percentil de $90 \%$ e classificação médio superior, o que indica que ela tem desempenho acima do esperado para sua idade cronológica.

Os resultados alcançados por Susan nos testes supracitados permitem constatar que ela apresenta um potencial cognitivo acima do esperado para sua etapa de desenvolvimento.

\section{Aspectos Neuropsicológicos}

A atenção de Susan foi avaliada por meio da Bateria Psicológica para Avaliação da Atenção (RUEDA, 2013). A atenção relaciona-se com "a capacidade de a pessoa selecionar e manter o controle da entrada de informações externas e o processamento de informações internas necessárias em um determinado momento" (FERNANDES \& RUEDA, 2007, p.169). Ela é uma das funções cognitivas e pode ser classificada em diferentes tipos, a saber: geral, alternada, dividida e concentrada (RUEDA, 2013).

Susan tem um índice superior na atenção geral, com percentil de $97 \%$ e 350 pontos ponderados. Em atenção concentrada tem índice superior, atinge percentil 80\% e 114 pontos. Em atenção dividida tem índice superior, percentil 95\% e 120 pontos. Em atenção alternada tem índice médio superior, percentil $70 \%$ e 116 pontos.

Outro constructo avaliado foi a memória imediata usando do instrumento chamado Figuras Complexas de Rey. As Figuras Complexas de Rey objetivam avaliar funções neuropsicológicas de percepção visual e memória imediata por meio de cópia e reprodução de memória. Seu objetivo é verificar o modo como o sujeito apreende os dados perceptivos que lhe são apresentados e o que foi conservado 
espontaneamente pela memória. As figuras propostas nesse teste reúnem três propriedades importantes, a ausência de significado evidente, a realização gráfica fácil e a estrutura do conjunto suficientemente complicada para solicitar uma atividade perceptiva analítica e organizadora (REY; OLIVEIRA; RIGONI, 2017) .

De acordo com a análise das respostas de Susan, observa-se classificação superior com alcance de percentil $100 \%$ na análise da cópia, o que demonstra uma cópia acima da média ao esperado para sua idade cronológica. Em análise de memória, a avaliada atingiu classificação superior com alcance de percentil 95\%, indicando grande facilidade de memória imediata, relacionada à capacidade de lembrar elementos e suas localizações por meio de desenhos precisos.

\section{Aspectos Emocionais e de Personalidade}

Para análise do domínio emocional adotou-se o instrumento intitulado Casa - Árvore - Pessoa: Técnica Projetiva de Desenho (HTP) (ALVES; TARDIVO, 2003) que tem como objetivo "compreender aspectos da personalidade do indivíduo, bem como a forma deste indivíduo de interagir com as pessoas e com o ambiente. O HTP estimula a projeção de elementos da personalidade e de áreas de conflito dentro da situação terapêutica e proporciona uma compreensão dinâmica das características e do funcionamento do sujeito" (BORSA, 2010, p. 152).

Os dados alcançados sugerem que Susan tem um nível de energia adequado à sua faixa etária e mostra lidar de maneira favorável na canalização e expressão de suas emoções. Demonstra aspectos e indicadores de um curso de desenvolvimento saudável e esperado. No entanto, é possível perceber certo nível de ansiedade e uma tendência a adotar uma postura autocrítica bastante acentuada, com uma possibilidade de ser muito exigente consigo mesma, gerando sentimentos de angústia.

Complementou-se a avaliação com o instrumento

Inventário Fatorial de Personalidade (IFP) que tem por objetivo traçar o perfil de personalidade do indivíduo, com base em 13 necessidades ou motivos psicológicos: Assistência, Intracepção, Afago, Autonomia, Deferência, Afiliação, Dominância, Desempenho, Exibição, Agressão, Ordem, Persistência e Mudança. Avalia também os Fatores de segunda ordem: Necessidades afetivas; Necessidades de organização e Necessidade de controle e oposição (LEME; RABELO; ALVES, 2013).

Os dados evidenciados por Susan sugerem performance superior nas dimensões Persistência, Desempenho, Dominância, Deferência, Intracepção e Assistência.

Altos níveis em persistência indicam uma tendência de se dedicar a qualquer trabalho iniciado por mais difícil que possa parecer, debruçando-se significativamente para alcançar resultados. Esta é uma dimensão que se relaciona a desempenho, que refere-se ao empenho para dominar, manipular e organizar 
dados e ideias, destacando-se sua capacidade de atuar de forma independente e autônoma, com maior rapidez possível, vencendo obstáculos e mantendo altos níveis de realização.

Revela também sentimentos de autoconfiança e traços de liderança. Em situações nas quais é liderada tem necessidade de admirar seu superior. Procura adotar uma postura empática, agindo com sentimentos de compaixão e justiça ao próximo, com maior afinidade por trabalhos que estejam alinhados aos seus valores e propósitos. Tem uma tendência a agir de forma introvertida e com facilidade para tarefas em que possa expressar sua criatividade e imaginação. Destaca-se pela capacidade de agir de forma parcial em suas opiniões. Calorosa, apaixonada, sensitiva e idealista, pode identificar-se com atuações nas quais tenha uma causa alinhada a seus valores e propósitos.

\section{Aspectos da Criatividade}

Para avaliação do potencial criativo, adotou-se o Estilos de Criar e Pensar (WECHSLER, 2006). Baseada na literatura e em pesquisas sobre as características de pessoas criativas, esta avaliação oferece informações sobre as formas preferenciais de pensar e agir que são mais condutivos à produção criativa e a inovação. Busca-se, deste modo, identificar os seus modos preferenciais de pensar e agir frente às diferentes circunstâncias de sua vida.

Os dados alcançados por Susan demonstram potencial criativo com estilo preferencial Inconformista Transformador, somando 106 pontos ponderados e percentil 66, caracterizando-a como questionadora, dinâmica e sonhadora. Tem facilidade em liderar pessoas, conseguindo inspirá-las no sentido de alcançar um objetivo maior. Tende a ser crítica, questionando regras. Tem preferência em agir em situações que possa desempenhar várias tarefas simultaneamente, utilizando sua imaginação e forma de solucionar problemas de maneira incomum.

\section{Aspectos das altas habilidades/superdotação}

Partindo das características de superdotação apresentadas na literatura, levando em consideração uma perspectiva multidimensional de identificação, além dos instrumentos padronizados supracitados que proveram indicadores importantes para investigação das $\mathrm{AH} / \mathrm{S}$ no perfil do sujeito, reuniu-se dados acerca da história de vida de Susan, a partir da contribuição da própria avaliada e da família (marido e mãe).

Ademais, utilizou-se do Questionário de Identificação de Indicadores de Altas Habilidades/Superdotação - Adulto - QIIAHSD - A e do Questionário de Identificação de Indicadores de Altas Habilidades/Superdotação - Adulto - $2^{\mathrm{a}}$ fonte - QIIAHSD - $2^{\mathrm{a}}$ fonte - (PÉREZ; FREITAS, 2016). 
Com base nas respostas advindas da família, da observação das avaliadoras e dos resultados alcançados por Susan, como também dos atributos identificados como presentes no curso do seu desenvolvimento por meio das falas coletadas, constata-se que ela demonstra elevada competência mnemônica, capacidade de raciocínio muito desenvolvida, necessidade de pouca informação para resolver demandas escolares, facilidade para aprender os conteúdos acadêmicos, vocabulário extenso, alta capacidade de abstração, habilidade avançada de compreensão e uso da linguagem, o que evidencia capacidade acima da média.

Susan apresenta grande número de ideias e soluções para os problemas, facilidade em resolver problemas usando métodos originais e tendência a fazer muitas perguntas. Além disso, é curiosa, é inventiva e questionadora. As referidas características subscrevem o anel da criatividade.

A avaliada demonstra persistência, segurança em suas convicções, dedica tempo e energia em termas de seu interesse, é exigente e evidencia tendência em responder às demandas, manifestando envolvimento com a tarefa. Tendo em vista as características supracitadas e os anéis circunscritos, pode-se constatar que Susan apresenta comportamentos de superdotação, conforme os pressupostos teóricos de Joseph Renzulli (2004; 2014).

\section{Discussão}

Os dados alcançados na avaliação de Susan permitem alguns entendimentos e corroboram com as características de superdotação apontadas na literatura (WINNER, 1998; GAMA, 2006). Quanto aos aspectos cognitivos, os altos índices alcançados nos testes padronizados demonstram que Susan evidencia habilidade acima da média ao que é esperado para sua faixa etária nas áreas de compreensão verbal, organização perceptual, velocidade de processamento e memória operacional, cujo QI total compreende percentil acima de $98 \%$. Os dados alcançados por Susan corroboram com a literatura, que destaca que a superdotação intelectual implica dispor de um grande potencial em pelo menos uma das áreas que compõem a inteligência humana (MOSQUERA; STOBAUS; FREITAS, 2013).

As concepções atuais de inteligência que a apresenta como um construto multidimensional, permitem que se considere diferentes influências no funcionamento do indivíduo, assim, considera-se que um mesmo indivíduo pode ter uma habilidade superior em uma área do conhecimento, posicionarse na média em outras, ou ainda, apresentar dificuldades em quaisquer campos do saber (ALENCAR, FLEITH, 2001; PANZERI, 2012; PALUDO, 2014). No entanto, no presente estudo, Susan alcança classificação superior e muito superior em todas as dimensões avaliadas.

Considerando ainda que a memória é um componente essencial aos processos cognitivos e diretamente relacionado ao aprendizado e realizações (PERLOW; JATTUSO; MOORE, 1997), os altos índices em atenção e memória da avaliada ressaltam sua facilidade e potencial para o aprendizado. 
Quanto aos aspectos de ajustamentos socioemocionais do superdotado, observa-se controvérsias e não há um consenso nos estudos. Observam-se discrepâncias entre as pesquisas a respeito da extensão em que crianças e jovens superdotados teriam maior pré-disposição para apresentar dificuldades sociais e emocionais, no entanto, verifica-se que não há evidência empírica que substancie tal posição (ALENCAR, 2007). No presente estudo, foi possível observar a presença de sentimentos de baixa autoestima e reduzido nível de autoconhecimento da avaliada sobre seu potencial, o que pode estar associado, por exemplo, à ausência de um atendimento direcionado no período escolar. Por outro lado, os dados também indicam altos índices de persistência, liderança, empatia, criticidade, paixão pelo aprendizado, capacidade de análise, gosto pelo desafio, habilidade em áreas específicas, interesse por assuntos e temas complexos e persistência perante dificuldades inesperadas, corroborando com achados de Pérez (2008).

Tendo em vista o objetivo central da presente avaliação psicológica, constata-se que Susan apresenta o perfil de superdotação. Isto significa que ela evidencia potencial/desempenho acima do que se espera para sua idade, com grande perspectiva de realização. Pérez (2008; 2012) ressalta que superdotados adultos quando formalmente identificados relatam o alívio do reconhecimento, fundamental para compreender e construir sua identidade como superdotado. Estudo conduzido por Vieira (2014) com adultos superdotados, identificados tardiamente, indica que o diagnóstico era recebido com surpresa, tanto a família como a pessoa avaliada percebiam seus comportamentos diferenciados, porém não entendiam como manifestações de AH/SD. Somente depois do processo de identificação estas situações adquiriram sentido para eles. Esta foi uma situação observada no presente estudo, pois Susan não acreditava que poderia ser superdotada. No entanto, após o diagnóstico, ela relata sentir-se aliviada e passa a entender melhor algumas de suas características.

Desta forma, é de suma importância a identificação das AH/S em qualquer momento da vida, pois permite encaminhamentos e intervenções adequadas. No entanto, na vida adulta, segundo Mosquera, et.al, (2013) o adulto jovem com AH/SD defronta-se com a tarefa de determinar sua relação com a comunidade, bem como elaborar um projeto de vida, de cunho filosófico e epistemológico, que o faça penetrar de maneira mais adequada no chamado período da adultez média. Neste sentido, destacase a relevância de se pensar no processo de avaliação e identificação do sujeito superdotado na vida adulta, como uma possibilidade de autoconhecimento e ressignificações de experiências e promoção do potencial. Diante do exposto, apresenta-se nesta oportunidade uma discussão em torno do processo de avaliação psicológica e identificação de sujeitos superdotados na vida adulta, tendo em vista a carência desse recorte de produção no contexto brasileiro. 


\section{Conclusões}

Diante da importância da identificação das altas habilidades/ superdotação, sobretudo na vida adulta, considerando os desafios e dificuldades inerentes a este processo, o presente estudo buscou contribuir para com o entendimento do tema, ressaltando a importância da avaliação em qualquer momento da vida do sujeito. Na adultez, no entanto, pode responder a questões importantes, resultantes de negligência e ausência de um processo de atendimento adequado durante a trajetória pregressa, que podem ter impactado na subvalorização de potencial. Assim, a avaliação psicológica demonstra contribuir para o autoconhecimento e fortalecimento do potencial, possibilitando novos direcionamentos na vida pessoal e profissional.

Enfatizou-se também a relevância da condução deste processo considerando diferentes constructos, obtendo uma avaliação completa e integral sobre o perfil da avaliada, com aspectos além da análise quantitativa de QI, aferido pelos testes de inteligência.

O estudo pode ser ampliado, com a possibilidade de aumentar a amostra, inclusive em outras regiões do país, já que analisou apenas um caso. De maneira geral, buscou-se contribuições sobre a avaliação psicológica em AH/S, vencendo a invisibilidade desta condição na vida adulta, desmistificando estereótipos e características, demonstrando sua importância e, deste modo, fomentando novas pesquisas.

\section{REFERÊNCIAS}

ALENCAR, Eunice Maria Soriano de. Características sócio-emocionais do superdotado: questões atuais. Psicologia em Estudo [online], Maringá, v. 12, n. 2, p. 371-378, ago. 2007. Disponível em: https://doi.org/10.1590/S1413-73722007000200018. Acesso em: 27 jun. 2021.

ALENCAR, Eunice Maria Soriano de; FLEITH, Denise. Superdotados: determinantes, educação e ajustamento. 2. ed. São Paulo: EPU, 2001.

ALI, Sana; RAFI, M Mohammed. New Strategies to identifying and empowering gifted underachievers. International Journal of Humanities Social Sciences and Education (IJHSSE), v. 3, n. 4, p. 84-89, 2016.

Disponível em: https://www.arcjournals.org/pdfs/ijhsse/v3-i4/10.pdf. Acesso em: 22 out. 2020.

ANASTASI, Anne; URBINA, Susana. Testagem psicológica. $7^{\text {a }}$ ed. Porto Alegre: Artes Médicas, 2000.

APA. Standards for Educational and Psychologicl Testing. New York: American Educational Research Association, 1999. 
BOCCALANDRO, Efraim Rojas. G36 teste não-verbal de inteligência: manual. São Paulo: Vetor, 2003.

BRODY, Linda. Meeting the individual educational needs of students by applying talent search principles to school settings. In: PLUCKER, Jonathan A.; RINN, Anne N.; MAKEL, Matthew C. (Eds.). From Giftedness to gifted education: reflecting theory in practice. Prufrock Press Inc: Waco, Texas, 2017. p. 43-63.

BORSA, Juliane. CONSIDERAÇÕES SOBRE O USO DO TESTE DA CASA-ÁRVORE-PESSOA HTP. Aval. psicol., Porto Alegre , v. 9, n. 1, p. 151-154, abr. 2010.

CAMPOS, Carolina Rosa et al. Avaliação Psicológica e intervenção: um estudo de caso sobre altas habilidades/superdotação. Revista Educação Especial, Santa Maria, v.32, p. 02-12, 2019. Disponível em: https://periodicos.ufsm.br/educacaoespecial/article/view/39550/pdf. Acesso em: 22 out. 2020.

CARROL, John B. Human Cognitive Abilities. Cambridge University Press, 1993.

CECILIO-FERNANDES, Dario; MARIN RUEDA, Fabián Javier. Evidência de validade concorrente para o Teste de Atenção Concentrada (TEACO-FF). Psic, São Paulo , v. 8, n. 2, p. $167-$

174, dez. 2007.

CONSELHO FEDERAL DE PSICOLOGIA. Suplemento Especial: testes psicológicos. Brasilia: Conselho Federal de Psicologia, 2004.

COSTA, Maria Pereira da; LUBART, Todd I. Gifted and talented children: heterogeneity and individual differences. Anales de psicología, v. 32, n. 3, p. 662-671, 2016. Disponível em: http://dx.doi.org/10.6018/analesps.32.3.259421. Acesso em: 22 out. 2020.

FERNANDEZ, Alicia. A Inteligência aprisionada: abordagem psicopedagógica clínica da criança e sua família. Porto Alegre: Artes Medicas, 1991.

GAMA, Maria Clara Sodré S. Educação de Superdotados: teoria e prática. São Paulo: EPU, 2006.

GARDNER, Howard. Inteligência: um conceito reformulado. Rio de Janeiro: Objetiva, 2000.

HERTZOG, Nancy B. et al. Identification of strengths and talents in young children. In: PFEIFFER, Steven I.; SHAUNESSY-DEDRICK, Elizabeth; FOLEY-NICPON, Megan (Eds.). APA Handbook of Giftedness and Talent. Washington, DC: American Psychological Association, p. 301-316, 2018. Disponível em: https://doi.org/10.1037/0000038-020. Acesso em: 22 out. 2020.

INTERNATIONAL TEST COMMISSION. International Test Commission Guidelines for Translating and Adapting Tests, 2010 Disponível em: http://www.intestcom.org. Acesso em: 22 out. 2020.

KAIL, Robert. Speed of information processing: Developmental change and links to intelligence. Journal of School Psychology, 38(1), p. 51-61, 2000. Disponível em:

https://www.researchgate.net/publication/247246907 Speed of Information Processing. Acesso em: 27 jun. 2021.

LEME, Irene F. Almeida de Sá; RABELO, Ivan Sant'Ana; ALVES, Gisele Aparecida da Silva. IFP-II: inventário fatorial de personalidade. São Paulo: Casa do Psicólogo, 2013.

MOSQUERA, Juan José Mouriño; STOBÄUS, Claus Dieter; FREITAS, Soraia Napoleão. Altas Habilidades/Superdotação: abordagem ao longo da vida. Revista Educação Especial. v. 26, n. 46, p. 401- 
420, maio/ago, 2013. Disponível em:

https://periodicos.ufsm.br/educacaoespecial/article/view/5371/pdf. Aceso em: 27 jun. 2021.

NORONHA, Ana Paula P. Os problemas mais graves e mais frequentes no uso dos testes psicológicos. Psicologia: Reflexão e Crítica, Porto Alegre, v. 15, n. 1, p. 135-142, 2002. Disponível em: https://www.scielo.br/pdf/prc/v15n1/a15v15n1.pdf. Acesso em 22 out. 2020.

OLIVEIRA, Margareth Silva; ROGONI, Maisa Santos. Figuras complexas de Rey: teste de cópia e de reprodução de memória de figuras geométricas complexas. São Paulo: Casa do Psicólogo, 2014

PALUDO, Karina Inês. Altas habilidades/superdotação sob a ótica do Sistema Teórico da Afetividade Ampliada: relações entre identidade e resiliência. 2014. 244f. Dissertação (Mestrado em Educação) - Programa de Pós-Graduação em Educação, Universidade Federal do Paraná. Curitiba (PR), 2014. Disponível em: https://acervodigital.ufpr.br/bitstream/handle/1884/32046/R\%20-\%20D\%20\%20KARINA\%20INES\%20PALUDO.pdf?sequence=1. Acesso em: 22 out. 2020.

PANZERI, M. V. Detección e identificación de altas capacidades intelectuales y creativas: una abordaje para el profesorado y los prefesionales de la educación y la salud. Buenos Aires: Nueva Librería, 2012.

PERLOW, Richard, JATUSSO, Mia; MOORE, D. D. Wayne. Role of verbal working memory in complex skill acquisition. Human Performance, v.10, n.3, p. 283-302, 1997. Disponível em: https://www.researchgate.net/publication/247502211 Role of Verbal Working Memory in Compl ex Skill Acquisition. Acesso em: 20 jun. 2021.

PÉREZ, Susana Graciela Pérez Barrera. Ser ou não ser, eis a questão: o processo de construção da identidade na pessoa com altas habilidades/superdotação adulta. 230 f. 2008. Tese (Doutorado em Educação) - Faculdade de Educação, Pontifícia Universidade Católica do Rio Grande do Sul, Porto Alegre, 2008. Disponível em: http://tede2.pucrs.br/tede2/bitstream/tede/3567/1/405524.pdf. Acesso em: 22 out. 2020.

PÉREZ, Susana Graciela Pérez Barrera; FREITAS, Soraia Napoleão. Manual de Identificação de altas habilidades/superdotação. Guarapuava: Apprehendere, 2016.

PÉREZ, Susana Graciela Pérez Barrera; FREITAS, Soraia Napoleão. A mulher com altas habilidades/superdotação: à procura de uma identidade. Rev. Bras. Ed. Esp., Marília, v. 18, n. 4, p. 677694, out.-dez., 2012. Disponível em:

https://www.scielo.br/j/rbee/a/qCDKrWPRqGSnZSsyRtxCCvm/?format=pdf\&lang=pt. Acesso em: 20 set. 2021.

PESSOTTO, Fernando; BARTHOLOMEU, Daniel. Guia prático das escalas Wechsler. São Paulo: Pearson, 2019.

PFEIFFER, Steven. Understanding success and psychological well-being of gifted kids and adolescents: Focusing on strengths of the heart. Estudos de Psicologia (Campinas), v. 35, n. 3, p. 259-263, jul-set. 2018. Disponível em: http://dx.doi.org/10.1590/1982-02752018000300004. Acesso em: 22 out. 2020.

PRIMI, Ricardo. Avaliação psicológica no Brasil: fundamentos, situação atual e direções para o futuro. Psicologia: teoria e prática, Brasília, v. 35, n. esp., p. 25-35, 2010. Disponível em: https: / www.scielo.br/scielo.php?script=sci arttext\&pid=S010237722010000. Acesso em: 22 out. 2020.

RENZULLI, Joseph. O que é esta coisa chamada Superdotação e como a desenvolvemos? uma retrospectiva de vinte e cinco anos. Revista Educação, Porto Alegre, v. 52, n. 1, , p.75-81, jan-abr, 2004. 
Disponível em: https://revistaseletronicas.pucrs.br/ojs/index.php/faced/article/view/375/272. Acesso em: 22 out. 2020.

RENZULLI, Joseph. A concepção de superdotação no modelo de três anéis: um modelo de desenvolvimento para promoção da produtividade criativa. In: VIRGOLIM, Angela Magda Rodrigues; KONKIEWITZ, Elisabeth Castelon (Orgs.). Altas habilidades/Superdotação, inteligência e criatividade: uma visão multidisciplinar: Campinas SP: Papirus. 2014, p. 219-264.

RUEDA, Fabián Javier Marín. Bateria Psicológica para Avaliação da Atenção - BPA. São Paulo: Vetor, 2013.

VIEIRA, Nara Joyce Wellausen. Identificação pela provisão: uma estratégia para a identificação das Altas Habilidades/Superdotação em adultos?. Revista Educação Especial (UFSM), 27(50), p. 699-712, set.dez, 2014. Disponível em: https://periodicos.ufsm.br/educacaoespecial/article/view/14324/pdf. Acesso em: 20 set. 2021.

VIRGOLIM, Angela Magda Rodrigues. Altas habilidades/superdotação: encorajando potenciais. Brasília: Ministério da Educação, Secretaria de Educação Especial, 2007. Disponível em: http://portal.mec.gov.br/seesp/arquivos/pdf/altashab1.pdf. Acesso em: 22 out. 2020.

WECHSLER, David. Escala Wechsler de inteligência para crianças: WISC-IV. Manual técnico. Trad. Maria de Lourdes Duprat. 4. ed. São Paulo: Casa do Psicólogo, 2013.

WECHSLER, David. WAIS-III: manual técnico. Trad. Maria Cecília Villena. São Paulo: Casa do Psicólogo, 2004.

WECHSLER, Solange Muglia. Estilos de Pensar e Criar: manual. Campinas: Impressão Digital do Brasil/LAMP, 2006.

WINNER, Ellen. Crianças superdotadas: mitos e realidades. Porto Alegre: Artes Médicas, 1998.

Recebido em: 12 de maio de 2021. Aprovado em: 20 de setembro de 2021. 